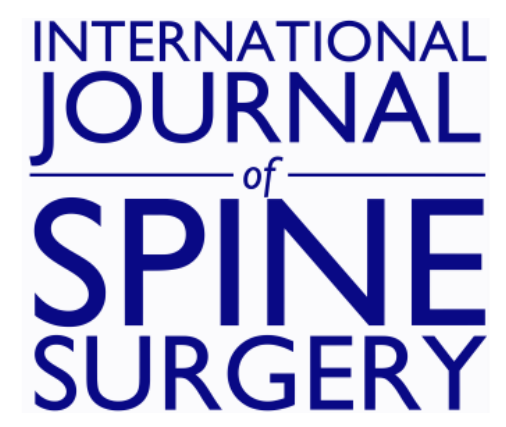

\title{
Painless squeaking following cervical disc replacement: A case report
}

Athar Siddiqui, Neil Wickham and Christopher Hulme

Int J Spine Surg 2015, 9 ()

doi: https://doi.org/10.14444/2044

http://ijssurgery.com/content/9/44

This information is current as of April 26, 2023.

Email Alerts Receive free email-alerts when new articles cite this article. Sign up at:

http://ijssurgery.com/alerts

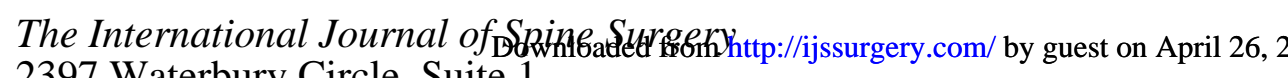
2397 Waterbury Circle, Suite 1,

Aurora, IL 60504, Phone: +1-630-375-1432 


\section{Painless squeaking following cervical disc replacement: A case}

report

Athar Siddiqui, MBBS MRCS DBS McH Orth Ed.,1 Neil Wickham, MBBcH MRCS, ${ }^{2}$ Christopher Hulme, MBBS(Lond) FRCS(Eng) FRCS(Tr \&Orth)

${ }_{1}^{1}$ Department of Trauma and Orthopedics, Epsom and St. Helier University Hospitals NHS Trust ${ }^{2}$ Department of Trauma and Orthopedics, St. Georges Healthcare NHS Trust

\section{Abstract}

\section{Background}

We present a case of painless squeaking following cervical disc replacement which to our knowledge has not previously been reported in the literature.

\section{Methods}

A 45 year old gentleman presented with severe right sided C6 radiculopathy. He complained of more than 6 weeks of severe dysaesthesia in the right arm with pain radiating into the hand, thumb, index, middle and ring fingers. MRI confirmed severe impingement of C6 and C7 nerve roots. After trying a period of conservative treatment he underwent anterior cervical decompression with total cervical disc replacement of C5-6 and C6-7.

\section{Results}

Being a keen athlete he started running at 6 months post operatively. At his 12 month outpatient he presented us with an audio file containing squeaking from his neck. This was recorded immediately following a 9.5 mile hard surface run. The squeak got progressively less in intensity over 12 hours and disappeared after 24 hours. All instances of squeaking occurred after exercise where impact (running) or vibration (cycling) took place. This was first noticed 6 months post operatively when he restarted exercising. All episodes were completely painless. At his 18 month outpatient review the squeaking had reduced in frequency and intensity. At his 24 month review it had abated completely.

\section{Conclusion}

The aetiology of this painless squeaking has been elusive and is likely to be multifactorial. However we hypothesise that the audible squeak associated with the prestige LP disc maybe related to specific design characteristics and needs further evaluation.

KEYWORDS: SQUEAKING, CERVICAL, TOTAL DISC ARTHROPLASTY, PRESTIGE LP DISC, CASE REPORT

VOLUME 9 ARTICLE 44 DOI: 10.14444/2044

\section{Introduction}

Compared with anterior cervical discectomy and fusion cervical disc arthroplasty can maintain the motion of intervertebral segment and decrease adjacent segment degeneration. The prestige LP disc

(Medtronic Sofamor Danek, Memphis, TN) is one of the most commonly used prostheses. It is a titanium ceramic composite ball and trough design with two articulating metal on metal components. ${ }^{1}$ Study data has shown superior clinical outcomes with disc implantation at 1 and 2 years when compared with anterior cervical discectomy and fusion. ${ }^{2}$ Furthermore, the favourable outcomes are maintained at 4 and 6 years of follow-up. ${ }^{2}$ Infrequently reported com- plications include neurological worsening, heterotopic ossification and kyphosis. We present a case of painless squeaking following cervical disc replacement which to our knowledge has not previously been reported in literature.

\section{Case report}

A 47 year old self-employed man who works in marketing and is also a keen runner presented to us with severe right sided $\mathrm{C} 6$ and $\mathrm{C} 7$ radiculopathy. His symptoms which had persisted for over 6 weeks were of severe dysaesthesia in the right arm with pain shooting down the arm into the hand, thumb, index, middle and ring finger. He underwent MRI of the 
cervical spine which confirmed severe impingement of the $\mathrm{C} 6$ and $\mathrm{C} 7$ nerve roots.

On examination he had no long tract signs but had a positive Spurling sign for radiculopathy down the right arm. His tone was normal bilaterally and symmetrically. His forearm flexion power was reduced to MRC Grade IV on the right compared to the left.

Initially he tried analgesia with NSAIDs, mild opiates and incrementally increased pregabalin to $600 \mathrm{mg}$ daily. However these failed to control his symptoms. After a reasonable period of conservative treatment we counselled the patient on surgical options. After careful consideration he was keen to proceed with surgical decompression of the affected nerve roots. This was via an anterior approach discectomy at C5-6 and C6-7 decompressing the $\mathrm{C} 6$ and $\mathrm{C} 7$ nerve roots. Given that he was approaching his fifth decade a total disc arthroplasty was suggested to use in the discectomy defect.

Soon afterwards he underwent C5-6 and C6-7 anterior cervical decompression and total disc arthroplasty. The surgery was complicated by a dural tear at the C6-7 level. This subsequently settled and he has no ongoing symptoms from this. The wounds healed well with minimal swelling and scarring.

The pain in the right arm, related to predominantly C6 \& C7 radicular distribution improved significantly postoperatively. He had some ongoing numbness immediately post op in the index and thumb tip however this also improved subsequently.

Being a keen athlete he started running lightly on hard and soft surfaces at 6 months post operatively. At his 12 month outpatient review when we were considering discharge due to his excellent clinical outcome, he presented us with an audio file containing squeaking from his neck. This had been recorded immediately following a 9.5 mile hard surface run. The sound was a high-pitched intermittent squeak although not particularly loud. It occurred following the run and continued to occur during normal flexion and extension movements. It got progressively less in intensity over the course of 12 hours and disappeared after 24 hours. The squeaking had occurred on a number of subsequent occasions only after some form of exercise where impact (running) or vibration (cycling) took place. The squeaking episodes were not triggered by normal activities of daily living although once triggered by exercise normal functional movement of the neck in flexion and extension resulted in squeaking. The phenomenon was first noticed 6 months post operatively when he restarted exercising. All episodes were completely painless. The squeaking persisted and was still troubling him at his 18 month review although he felt at this point it had decreased in frequency and duration. At 24 months the squeaking had abated completely and no longer occurred following the activity that typically preceded it. At 36 months he had not been troubled by squeaking for more than 12 months and had developed no further complications, at which point we discharged him from the outpatient clinic.

We investigated this phenomenon with plain radiographs of the cervical spine, MRI, Focussed CT scan and EMG Studies. These all confirmed excellent implant position and no further nerve root impingement. No explanation as to the cause of squeaking was elicited from these investigations. Below are the AP and Lateral radiographs of the patient at 24 months (Figure $1 \&$ Figure 2).

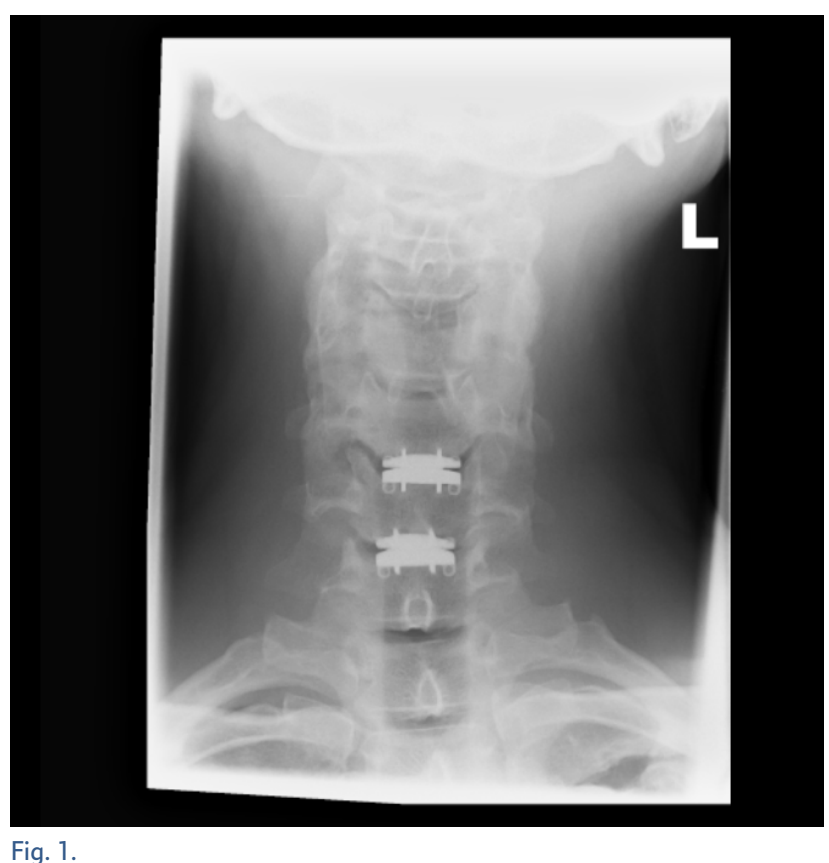




\section{Discussion}

The PRESTIGE LP arthroplasty (Medtronic Sofamor Danek) is a fifth generation device based on the Bristol-Cummins disc. The Bristol-Cummins disc is a ball and socket, metal on metal design used in Europe during the early 1990s. The BristolCummins disc was modified to the PRESTIGE I disc (Medtronic Sofamor Danek) in 1998, to the PRESTIGE II disc (Medtronic Sofamor Danek) in 1999, to the PRESTIGE ST device in 2002, and ultimately to the PRESTIGE LP device. The Bristol-Cummins disc, the PRESTIGE I, the PRESTIGE II, and the PRESTIGE ST devices are all stainless steel implants that use vertebral body screws to fix their position in the inter-space. The PRESTIGE LP disc is an artificial, cervical, titanium and ceramic composite disc which uses rails to provide initial friction against migration of the implant and a plasma spray coating on its superior and inferior surfaces to allow bony in-growth from the vertebral endplates onto the device$^{3}$ (Figure 3).

Squeaking following total hip arthroplasty is a well described phenomenon most commonly affecting ceramic on ceramic prosthesis. However it is also reported with metal on metal designs. ${ }^{4}$ Several explanations for squeaking in total hip arthroplasty have been proposed including; component malposition,

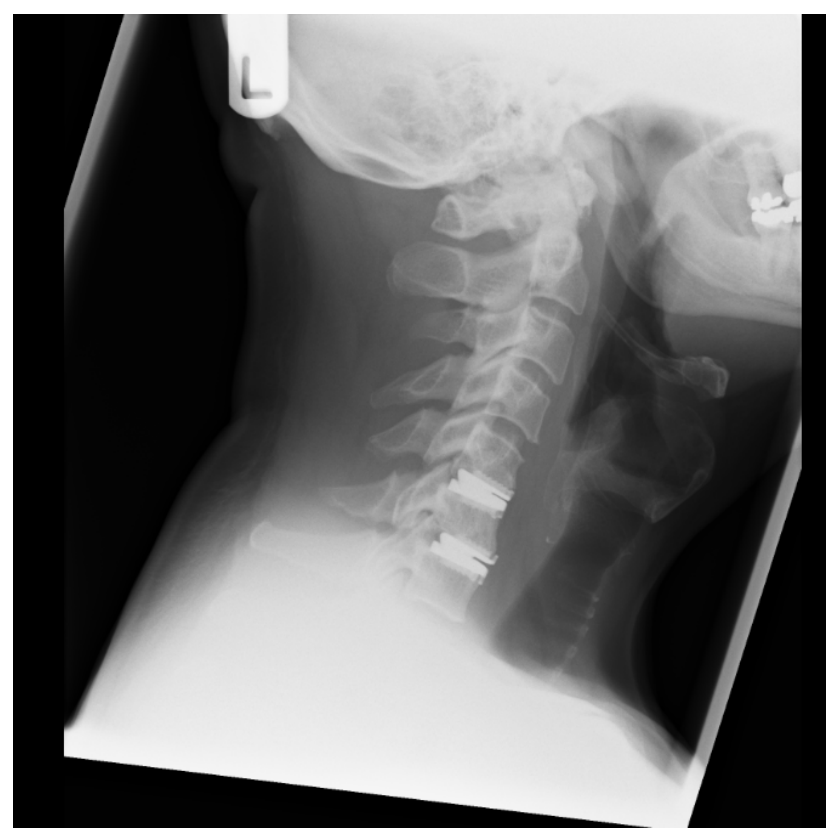

Fig. 2. edge loading, impingement, third-body particles, and loss of lubrication. ${ }^{5}$ It is likely that squeaking may represent a common manifestation of a number of different underlying causes or factors. In this case we were able to exclude several of these possible causes for squeaking with investigations including CT, MRI and EMG.

It is both noteworthy and a relief that the squeaking was self-limiting and had completely resolved by 2 years post operatively. One explanation maybe that the adjacent cervical vertebrae had fused during this time preventing articulation of the prosthesis and resultant squeaking. However without dynamic imaging or flexion / extension views to support this it remains speculative. It is also noteworthy that in total hip arthroplasty metal on metal prosthetic squeaking tends to abate with time as occurred with our patient. $^{6}$

It also reassuring that no other significant complication occurred in the early post operative period or subsequently over the 3 years of follow up. This suggests that no major mechanical defect or technical surgical error had occurred to cause the phenomenon. If the outcome had been less favourable or if further case reports emerge in the future it may be prudent to contact the manufacturers of the Prestige LP disc to avoid any potential adverse outcomes for patients. We hypothesise that a number of factors interacted in this case which may include the design characteristics of the Prestige LP disc itself resulting in this squeaking phenomenon.

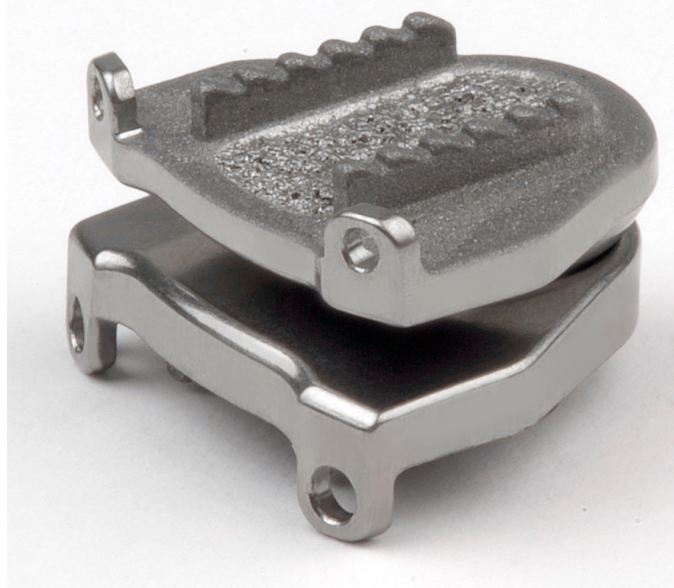

Fig. 3. Prestige LP prosthesis. 


\section{Conclusions}

This article describes a unique case of painless audible squeaking following cervical disc replacement the aetiology of which is elusive and is likely to be multifactorial. We hypothesise that the audible squeak associated with the prestige disc maybe related to specific design characteristics that may need further evaluation beyond the scope of this report.

\section{References}

1. http://www.prestigedisc.com/intl/aboutprestige-disc.html retrieved 12/12/2014.

2. Burkus JK, Haid RW, Traynelis VC, Mummaneni PV. Long-term clinical and radiographic outcomes of cervical disc replacement with the Prestige disc: results from a prospective randomized controlled clinical trial J Neurosurg Spine 13:308-318 2010.

3. Mummaneni PV, Robinson JC, Haid RW Jr. Cervical Arthroplasty with the Prestige LP Cervical Disc Neurosurgery 60[ONS Suppl 2]:ONS-310-ONS-315, 2007.

4. Esposito C, Walter WL, Campbell P, Roques A. Squeaking in metal-on-metal hip resurfacing arthro- plasties. Clin Orthop Relat Res. 2010 Sep;468(9):2333-9.

5. Walter WL, Yeung E, Esposito C. A review of squeaking hips. J Am Acad Orthop Surg. 2010 Jun;18(6):319-26.

6. Esposito C, Walter WL, Campbell P, Roques A. Squeaking in metal-on-metal hip resurfacing arthroplasties. Clin Orthop Relat Res. 2010

Sep;468(9):2333-9.

\section{Disclosures}

The authors report no relevant disclosures.

\section{Corresponding Author}

Mr Neil Wickham, Department of Trauma and Orthopedics, St George's Hospital, Blackshaw Road, Tooting, South West London SW17 0QT.

Published 12 August 2015.

This manuscript is generously published free of charge by ISASS, the International Society for the Advancement of Spine Surgery. Copyright @ 2015 ISASS. To see more or order reprints or permissions, see http://ijssurgery.com. 